\title{
Targeted therapy in severe asthma today: focus on immunoglobulin $\mathrm{E}$
}

This article was published in the following Dove Press journal:

Drug Design, Development and Therapy

29 June 2017

Number of times this article has been viewed

\section{Girolamo Pelaia' \\ Giorgio Walter \\ Canonica ${ }^{2}$ \\ Andrea Matucci ${ }^{3}$ \\ Rossella Paolini ${ }^{4}$ \\ Massimo Triggiani ${ }^{5}$ \\ Pierluigi Paggiaro ${ }^{6}$}

'Department of Medical and Surgical Sciences, Section of Respiratory Diseases, University Magna Graecia of Catanzaro, Catanzaro, ${ }^{2}$ Personalized Medicine Asthma \& Allergy Clinic, Humanitas University, IRCCS Humanitas Research Hospital, Rozzano-Milano, ${ }^{3}$ Immunoallergology Unit, AOU Careggi, Florence,

${ }^{4}$ Department of Molecular Medicine,

"Sapienza" University of Rome, Laboratory affiliated to Istituto Pasteur Italia - Fondazione Cenci Bolognetti, Rome, ${ }^{5}$ Division of Allergy and Clinical Immunology, University of Salerno, Salerno, ${ }^{6}$ Cardio Thoracic and Vascular Department, Pathophysiology Unit, University of Pisa, Pisa, Italy
Correspondence: Girolamo Pelaia Department of Medical and Surgical Sciences, Section of Respiratory Diseases, University "Magna Graecia” of Catanzaro, Campus Universitario "S. Venuta" Viale Europa, Località Germaneto, 88100

Catanzaro, Italy

Tel +3996I 3647302

Fax +39 96I 3647193

Email pelaia@unicz.it

\begin{abstract}
Asthma is a complex chronic inflammatory disease of multifactorial etiology. International guidelines increasingly recognize that a standard "one size fits all" approach is no longer an effective approach to achieve optimal treatment outcomes, and a number of disease phenotypes have been proposed for asthma, which has the potential to guide treatment decisions. Among the many asthma phenotypes, allergic asthma represents the widest and most easily recognized asthma phenotype, present in up to two-thirds of adults with asthma. Immunoglobulin $\mathrm{E}$ ( $\mathrm{IgE}$ ) production is the primary and key cause of allergic asthma leading to persistent symptoms, exacerbations and a poor quality of life. Therefore, limiting IgE activity upstream could stop the entire allergic inflammation cascade in IgE-mediated allergic asthma. The anti-IgE treatment omalizumab has an accepted place in the management of severe asthma (Global Initiative for Asthma [GINA] step 5) and represents the first (and, currently, only) targeted therapy with a specific target in severe allergic asthma. This review summarizes current knowledge of the mechanisms and pathogenesis of severe asthma, examines the actual role of $\operatorname{IgE}$ in asthma and the biological rationale for targeting $\operatorname{IgE}$ in allergic asthma and reviews the data for the efficacy and safety of omalizumab in the treatment of severe asthma. Current knowledge of the role of IgE in asthma, extensive clinical trial data and a decade of use in clinical practice has established omalizumab as a safe and effective targeted therapy for the treatment of patients with severe persistent IgE-mediated allergic asthma.
\end{abstract}

Keywords: anti-immunoglobulin E, allergic asthma, Global Initiative for Asthma step 5 therapy, severe persistent asthma, omalizumab, phenotypes, targeted therapy

\section{Introduction}

Asthma is now considered an inflammatory chronic disease of multifactorial etiology. Initially, asthma was described as a typical eosinophilic airway inflammation, often sustained by allergic sensitization, which led to bronchial hyperresponsiveness and acute bronchoconstriction in response to specific and nonspecific triggers. ${ }^{1}$ Later on, it became clearer that different inflammatory and noninflammatory mechanisms may be responsible for the development and progression of asthma; airway neutrophilic inflammation has been described in subgroups of asthmatic patients, ${ }^{2}$ particularly those with severe asthma, ${ }^{3}$ and also a paucigranulocytic airway inflammation has been reported in some asthma phenotypes, such as asthmatics with obesity and/or gastro-esophageal reflux. ${ }^{4}$ This "non-eosinophilic" inflammatory phenotype seems fairly stable over time. ${ }^{2,5}$ This led to the opinion that "the common disease asthma is probably not a single disease, but rather a complex of multiple, separate syndromes that overlap". 6

According to this view, the new Global Initiative for Asthma (GINA) strategy document for asthma management and prevention defines the condition as a 
"heterogeneous disease, usually characterized by chronic airway inflammation", with the presence of respiratory symptoms and functional abnormalities. ${ }^{7}$ This heterogeneity may be related to the inducing mechanisms and triggers (allergic vs nonallergic), the pathologic background (eosinophilic vs non-eosinophilic inflammation), the clinical manifestations (in terms of severity, frequency of exacerbations, response to treatment) and the outcomes (remission or progression to non-reversible airway obstruction). Several associated conditions or comorbidities (upper airway diseases, obesity, smoking habit, etc) may modify the clinical expression of the disease. A major consequence of this new asthma definition is that, in light of the poor specificity of symptoms, risk factors and pathologic background, pulmonary function assessment now plays a crucial role in the diagnosis of the disease; in particular, the wide variability over time of forced expiratory volume in 1 second $\left(\mathrm{FEV}_{1}\right)$ may be now considered the main diagnostic criterion for asthma.

The goal of treatment in patients with asthma is to achieve a good control of symptoms and to reduce the "future risk", as expressed by the risk of future exacerbations, loss of asthma control, progressive decline in pulmonary function or drugrelated side effects. ${ }^{8}$ All international guidelines suggest to adapt the level of treatment to the level of severity/control of the disease $\mathrm{e}^{7,9,10}$ using a standard approach, which has been demonstrated as effective in the large majority of unselected asthmatic patients. However, a "one-size-fits-all" therapeutic strategy no longer appears appropriate to effectively pursue these goals, given the heterogeneity of disease. Furthermore, although patients with severe disease represent only $5 \%-10 \%$ of the total number of subjects with asthma, this small population consumes a disproportionate amount of the global asthma budget $(\sim 50 \%)$ due to unscheduled health care utilization in primary care, hospitalizations due to severe exacerbations and the costs of pharmacotherapy. ${ }^{11,12}$ For this reason, a great deal of attention has been focused in the last few years toward better assessment and management of patients with severe asthma. This approach has been clearly mentioned in the new GINA document, ${ }^{7}$ where, when population-level decisions about asthma treatment are under consideration, the outlined "preferred option" to be taken at each step represents the best treatment for most patients, based on the best available evidence from the efficacy, effectiveness and safety data of randomized controlled trials, meta-analyses and observational studies, together with considerations of net cost. However, treatment decisions for individual patients should also consider any patient characteristics or phenotype that is able to predict the patient's likely response to treatment, in addition to patient preferences and practical issues such as inhaler technique, adherence and the cost to the patient. ${ }^{7}$

In line with the concept of the heterogeneity of asthma, a number of disease phenotypes have been proposed over the recent years, also taking into account the different inflammatory origins of the disease (Table 1). ${ }^{6}$ Phenotypes can play a role in guiding treatment decisions. Several examples may be described: omalizumab in severe allergic asthma, allergen immunotherapy in allergic asthmatics, ${ }^{13}$ montelukast in asthma plus allergic rhinitis or exercise-induced asthma $^{14}$ and tiotropium in severe asthmatics with persistent bronchoconstriction. ${ }^{15}$ This is particularly relevant in more severe categories of asthma, where the heterogeneity of the disease may really require a "personalized therapy" in the presence of a lack of adequate asthma control with the current pharmacologic therapies. In effect, the current approach to asthma management and treatment as reported in the GINA guidelines is a traditional approach in the first four steps; the approach of "reactive medicine" is used. In GINA step 5, a "targeted medicine" approach is the recommended option, which is where omalizumab, a humanized monoclonal antibody that selectively targets immunoglobulin E (IgE), is positioned. ${ }^{7}$ In fact, nowadays the evolution from "empirical medicine" to "precision medicine" in several chronic diseases is highlighted. This evolution is present in asthma too, mainly in severe asthma, where costly treatments will find appropriate positioning.

The so-called "omics" sciences such as genomics and proteomics are providing new tools to facilitate discoverydriven studies on new and reliable biomarkers that can

Table I Main asthma phenotypes, according to clinical manifestations, inducers/trigger factors and inflammatory pattern

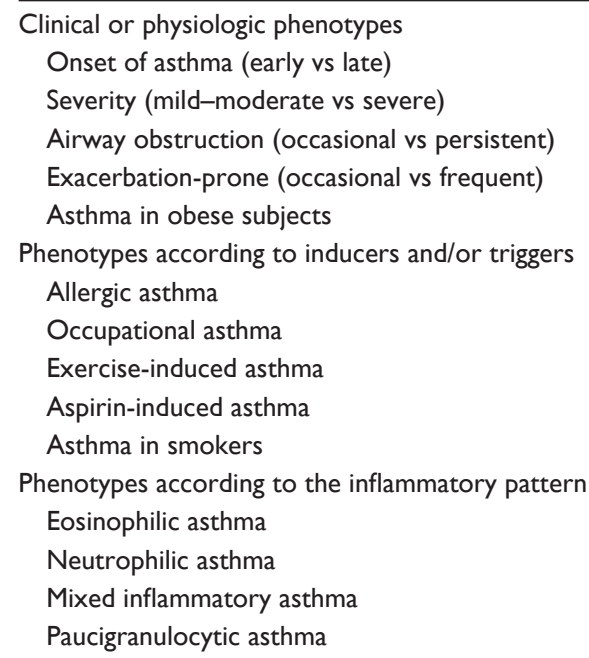

Note: Data from Wenzel. ${ }^{6}$ 
predict response to therapy, help identify patients who are more suitable for a given treatment and provide a focus for the development of targeted therapies. ${ }^{16}$ New treatments such as biological therapies are now available that modify specific pathogenic mechanisms based on precise genotype characterization in the individual patient. This represents the first step toward personalized therapy for asthma patients, especially for those with more severe disease. ${ }^{17,18}$

There is increasing awareness of the role of $\operatorname{IgE}$ in allergic asthma. Therefore, we undertook a review aimed at summarizing the current knowledge of the mechanisms and pathogenesis of severe asthma, with particular focus on examining the role of $\operatorname{IgE}$ and the biological rationale for targeting IgE in allergic asthma.

\section{Biological rationale for IgE as a therapeutic target in allergic asthma}

Over recent decades, the key role of IgE in the pathophysiology of allergic asthma has been recognized. ${ }^{19}$ IgEs have been identified as central players of allergic asthma, regulating a network that involves specific receptors expressed on a broad array of immune cells and also on airway tissue structural cells.

\section{Membrane receptors for $\lg \mathrm{E}$}

The high-affinity IgE receptor (FceRI) is constitutively expressed on mast cells and basophils as a tetrameric complex composed of an IgE-binding $\alpha$ subunit, a four-transmembranespanning $\beta$ subunit and two identical disulfide-linked $\gamma$ subunits. ${ }^{20}$ Wan et $\mathrm{al}^{21}$ demonstrated that $\mathrm{IgE}$ binding to the FceRI $\alpha$ chain involves the C $\varepsilon 3$ domain pair of IgE, which is also the binding site for omalizumab.

In humans, a trimeric complex lacking the $\beta$ chain $\left(\right.$ FceRI $\left.\alpha \gamma_{2}\right)$ also exists and is expressed by the professional antigen-presenting cells (APCs) and a wide variety of other cell types, including airway smooth muscle cells (ASMCs) and airway epithelial cells (AECs) of asthmatic patients. ${ }^{22,23}$

The low-affinity IgE receptor (FceRII or CD23) is transcribed in two spliced isoforms, CD23a and CD23b, with CD23a being constitutively expressed on B cells and CD23b, upon interleukin (IL)-4 activation, on several cell types, including APCs, eosinophils, neutrophils and human bronchial epithelial cells. ${ }^{24}$

IgE regulates the expression of both high- and low-affinity receptors. A direct correlation between total serum IgE levels and FceRI surface expression has been reported for human basophils, monocytes and dendritic cells (DCs). ${ }^{25-27}$
Similarly, IgE binding to CD23 inhibits receptor cleavage by proteases, thus allowing the IgE-CD23 complex to stabilize on the cell surface. ${ }^{28}$ Conversely, the unoccupied membrane form of $\mathrm{CD} 23$ is highly susceptible to proteolytic cleavage, ${ }^{29}$ leading to the release of a free receptor known as soluble $\mathrm{CD} 23$ (sCD23), which retains the capability to bind IgE.

sCD23 and other two human soluble IgE receptors, namely, soluble FceRI (sFceRI) and galectin-3, represent additional elements of the IgE network. ${ }^{30}$

\section{Biological functions of the lgE network on mast cells and basophils}

The ligation of allergen to FceRI-bound IgE on mast cells and basophils initiates a signaling cascade leading to the release of preformed and de novo synthesized mediators. A classic "early-phase" reaction is characterized by vasodilation, increased vascular permeability, upregulation of adhesion molecules and contraction of smooth muscle cells, whereas the "late-phase" reaction leads to the production of cytokines that orchestrate the recruitment and activation of several immune cells. ${ }^{31}$

Signaling events involved in regulating FceRI-mediated mast cell and basophil activation and the role of these effector cells in the pathophysiology of asthma have been reviewed extensively. ${ }^{19,31,32}$ Notably, a positive-feedback regulation of FceRI expression on mast cells and basophils is provided by monomeric IgE in the absence of allergen cross-linking (Box 1), whereas, upon receptor engagement, a negativefeedback regulation is provided by receptor ubiquitination that represents a signal for endocytosis and lysosomal degradation of engaged receptor complexes. ${ }^{33}$

\section{$\lg \mathrm{E}$ and the biological activities of DCs}

DCs, typical of professional APCs, can provide all the known co-stimulatory signals required for activation of naive $\mathrm{T}$ cells. DCs are present in an extended and highly intricate network at the level of the respiratory mucosa; they can uptake inhalant allergen molecules, process and transport them to the regional lymph nodes, where DCs can present the peptides to specific T cells. Among membrane receptors of DCs, the FceRI mediates IgE-dependent allergen presentation. ${ }^{22,34}$

In addition to their constitutive presence within environmentally accessible organs, eg, skin and mucosal tissues, FceRI-expressing APCs circulate in peripheral blood and, upon allergen challenge, may enter sites of ongoing allergic inflammation, eg, airway walls. With low concentration of allergens within such tissues, the expression of FceRI on 
Box I lgE and mast cell/basophil homeostasis

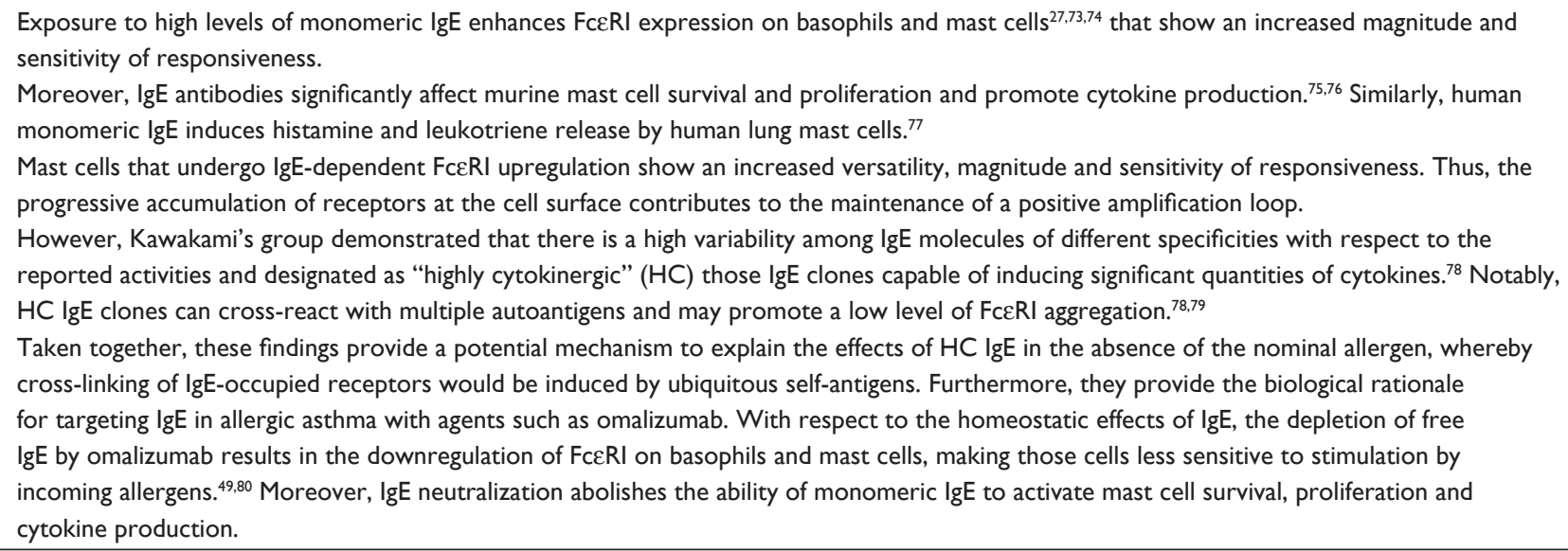

Abbreviation: IgE, immunoglobulin E.

APCs by atopic individuals may critically promote allergen uptake, processing and presentation, thus ensuring allergenspecific T-cell responses. ${ }^{19}$ FceRI-IgE-dependent allergen presentation may hence critically lower the atopic individual's threshold to mount allergen-specific T-cell responses. In fact, the targeting of allergens to FceRI via IgE leads to a 1,000-fold increase in the activation of $\mathrm{T}$ cells and to the production of CCL28, a chemokine that selectively attracts T helper (Th) 2 lymphocytes. ${ }^{35,36}$ Consequently, such activation of allergen-specific Th cells may result in the perpetuation of allergen-specific IgE production and, thus, of type I reactions and possibly even the induction of delayed-type hypersensitivity reactions in allergen-exposed tissues. ${ }^{34}$

The effect of the IgE network on DCs is still more complex, taking into account that FceRI on monocytes can lead to IL-10 production preventing their in vitro differentiation in DCs. ${ }^{37}$ This modulation of APC differentiation promotes a less efficient T-cell activation, suggesting a contribution of FceRI in the downregulation of the inflammation. Furthermore, FceRI is a negative regulator of plasmacytoid DC interferon-I production through the activation of immunoglobulin-like transcript 7, an inhibitory receptor bearing an immunoreceptor tyrosine-based activating motif-based activation motif. ${ }^{38}$

\section{Expression and putative functions of $\lg E$ receptors on human eosinophils and macrophages}

Human eosinophils develop as mature cells in the bone marrow, and they usually have a short (24-48-hour) lifespan in the blood. Under normal circumstances, these cells do not accumulate within peripheral tissues unless they are recruited locally by specific proinflammatory cytokines and chemokines. Early studies demonstrated that human blood eosinophils express mRNA for all chains $(\alpha, \beta$ and $\gamma)$ of the high-affinity IgE receptor. ${ }^{39-41}$ In diseases associated with high IgE and eosinophilia, surface expression of the FceRI has been detected in both blood and tissue eosinophils. However, the level of membrane expression is usually low, and its detection is often complicated by the presence of intracellular stores of the receptor. Human eosinophils also express FceRII that, together with FceRI, have been associated with the anti-parasitic function of these cells. ${ }^{39}$ Increased expression of either the high- or low-affinity IgE receptor on eosinophils has been associated with their recruitment in hypereosinophilic disorders.

Despite being fully saturated by IgE, the mechanisms of activation and the responses elicited by FceRI engagement on eosinophils are still undefined. Studies in vitro failed to demonstrate degranulation of eosinophils by cross-linking of IgE on their surface. ${ }^{42}$ Thus, the real function of this receptor on human eosinophils still remains elusive.

Macrophages are ubiquitous cells developed by differentiation and maturation of blood monocytes recruited within peripheral tissues. These cells play a primary role in innate immunity, regulating local tissue inflammation, injury and remodeling. IgE-mediated activation of macrophages through FceRI has been demonstrated in a murine and human model of aortic aneurysm development. ${ }^{43}$

IgE activation of macrophages leads to the release of IL-6, MCP-1 and other proinflammatory cytokines, as well as to macrophage apoptosis. ${ }^{43}$ Furthermore, FceRI stimulation promotes the generation of macrophage-like cells expressing the $\mathrm{H} 1$ receptor for histamine with enhanced histamine biosynthesis and histamine-mediated proinflammatory 
properties. ${ }^{44}$ Supporting these in vitro findings, high numbers of histamine $\mathrm{H} 1$ receptor-expressing CD68+ macrophages were detected in the dermis of atopic dermatitis skin lesions. ${ }^{44}$ These results support the hypothesis of a functionally active FceRI expression on human macrophages involved in the proinflammatory and tissue remodeling activity of these cells.

\section{IgE and smooth muscle cell function}

ASMCs are one type of the main structural cells of the airway walls, considered for many years only as contracting elements involved in bronchoconstriction during acute exacerbations of asthma.

The activation of ASMCs is a crucial step of asthma pathophysiology. In fact, smooth muscle thickening in asthma is a consequence of both hypertrophy and hyperplasia, both of which correlate with asthma severity. ${ }^{45}$ In addition to their physical properties, ASMCs can participate in inflammatory processes through the release of a variety of inflammatory cytokines and chemokines, modulating the initiation, amplification and perhaps resolution of airway inflammation. Upon stimulation or interaction with immune cells, ASMCs produce and secrete extracellular matrix proteins that are key factors actively involved in the remodeling of airway walls. The activation of ASMCs is the consequence not only of the direct effect on these cells by preformed mediators released by mast cells and basophils during the acute allergic reaction but also through the involvement of $\operatorname{IgE}$ fixed on their surface, in that they express FceRI. ${ }^{23}$ The activation of FceRI on ASMCs suggests a critical yet almost completely ignored network, which may modulate the function of this type of cells in allergic asthma.

The major effect of $\operatorname{IgE}$ on remodeling is mediated via FceRI and explains the release of collagen type-I and -III by ASMCs, as well as their proliferation. ${ }^{46}$

\section{IgE network and AEC functions}

The epithelial airway tract and allergen-specific IgE are considered essential regulators of inflammatory responses to allergens. Indeed, the low-affinity $\operatorname{IgE}$ receptor, CD23, is expressed on AECs and acts as a transporter of $\operatorname{IgE}$ or $\mathrm{IgE}$-allergen complexes across the polarized airway mucosal barrier both in vitro and in vivo. ${ }^{47,48}$

The mechanism of transport mediated by CD23 implies that the IgE produced locally by B lymphocytes is recognized by the receptor on the apical membrane of AECs and released into the lumen, resulting in binding inhaled allergens to form immune complexes. They would then be transported in the opposite direction where they could engage the FceRI expressed by sensitized mast cells promoting their degranulation and be captured and processed by DCs, thus facilitating presentation to Th2 cells. Since AECs are the first cells to come into contact with the allergen assumed by inhalation, this mechanism plays a pivotal role in the initiation and development of airway allergic inflammation. ${ }^{47}$

In summary, targeting the inflammatory and allergic process can be considered a valid approach to control the symptoms of severe allergic asthma. In this respect, omalizumab selectively binds free IgE molecules, blocking the binding site for both FceRI and CD23, modulating and acting upstream of the IgE network and slowing or preventing the allergic inflammatory cascade. ${ }^{49} \mathrm{~A}$ schematic representation of the biological function of the $\operatorname{IgE}$ network and the possible effects of omalizumab is shown in Figure 1. Thus, treatment with omalizumab provides the unique opportunity of blocking both the allergen-specific airway response and the initiation and development of chronic airway allergic inflammation.

\section{Targeting IgE in allergic asthma: from theory to practical application}

Omalizumab is currently the only available IgE-targeted therapeutic agent, approved for patients with severe allergic asthma and high IgE blood levels.

Initial clinical studies evaluating the efficacy of omalizumab in asthma showed that this anti-IgE monoclonal antibody significantly inhibited early- and late-phase asthmatic reactions, triggered by inhaled allergens..$^{50}$ Subsequently, a series of randomized controlled trials have shown that add-on treatment with omalizumab is very effective in reducing respiratory symptoms and especially asthma exacerbations, hospitalizations, emergency room visits and consumption of oral corticosteroids in patients with moderate-tosevere asthma. ${ }^{51-53}$

Specifically, omalizumab has been shown to significantly decrease severe disease exacerbations in subjects with uncontrolled allergic asthma. ${ }^{54-56}$ Furthermore, omalizumab as add-on therapy in patients with moderate-to-severe asthma and concomitant rhinitis markedly improved both Asthma Quality-of-Life Questionnaire (AQLQ) and Rhinitis Qualityof-Life Questionnaire (RQLQ) scores. ${ }^{57}$ These results are very important because of the high relevance of allergic rhinitis as one of the most prevalent asthma comorbidities.

The Investigation of Omalizumab in Severe Asthma Treatment (INNOVATE) study was a pivotal study in 419 allergic subjects with uncontrolled severe asthma, characterized by recurrent disease exacerbations and marked bronchial 


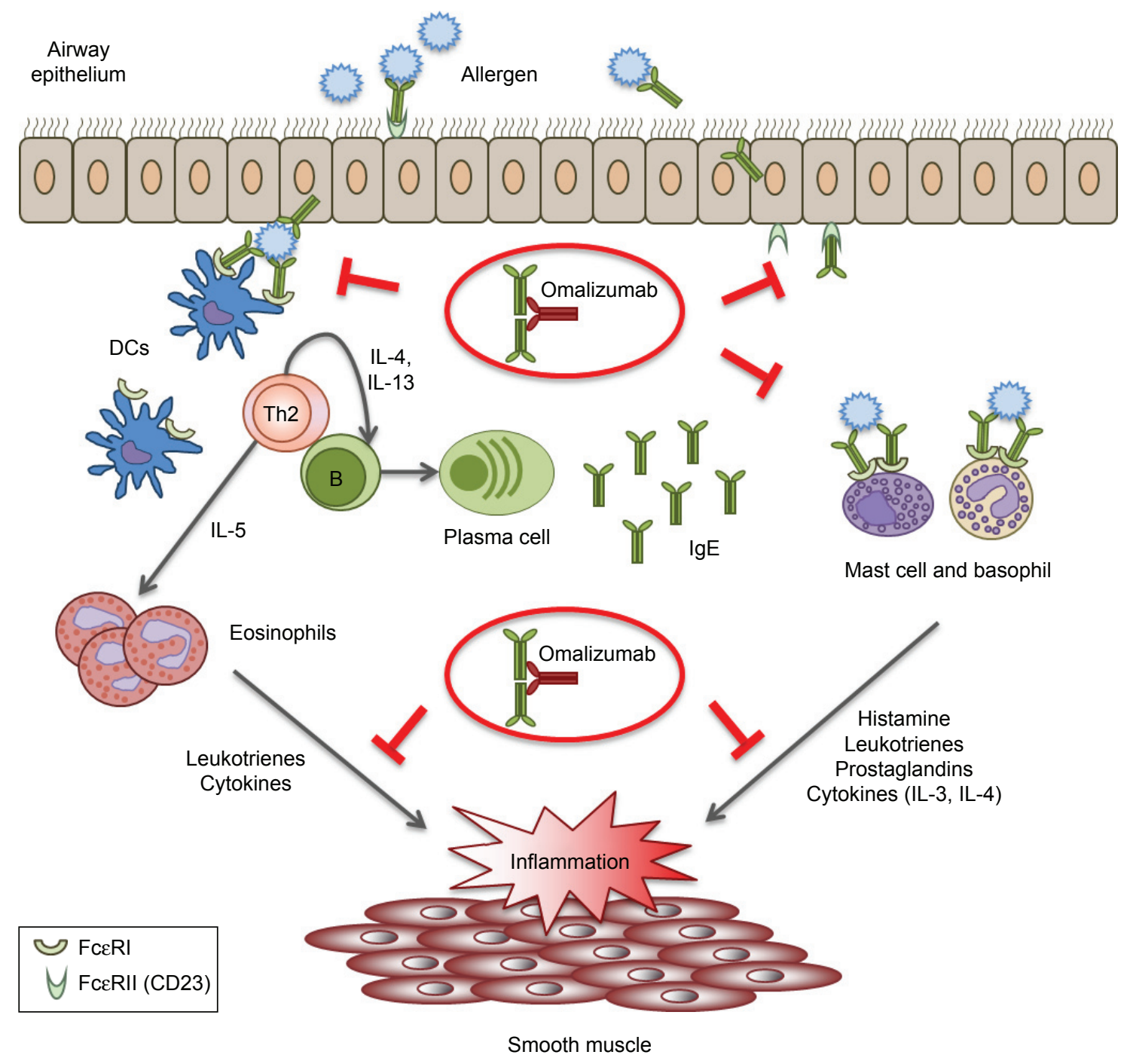

Figure I Schematic representation of the biological functions of the IgE network, which are inhibited by omalizumab.

Notes: Republished with permission of J Allergy Clin Immunol Pract, from Omalizumab in asthma: an update on recent developments. Humbert M, Busse W, Hanania NA, et al. Vol 2(5). Copyright 20I4; permission conveyed through Copyright Clearance Center, Inc. ${ }^{72}$

Abbreviations: IgE, immunoglobulin E; DCs, dendritic cells; Th, T helper; IL, interleukin.

obstruction (baseline $\mathrm{FEV}_{1} \geq 40 \%-<80 \%$ predicted). Asthma exacerbations, emergency visits and requirements of oral corticosteroids significantly decreased in patients undergoing 28-week add-on anti-IgE therapy with omalizumab, compared with placebo. ${ }^{58}$ These findings have been confirmed in 850 asthmatic patients with a wide age range (12-75 years), who underwent a comparative evaluation of omalizumab versus placebo after 48 weeks of add-on treatment, in which omalizumab significantly lowered asthma symptoms and exacerbations and also reduced the daily need for short-acting rescue bronchodilators. ${ }^{59}$ Treatment with omalizumab has also been shown to be accompanied by relevant improvements in quality of life, asthma symptoms and peak expiratory flow. ${ }^{58}$ Of particular interest, 60 weeks of add-on treatment with omalizumab significantly improved asthma control and prevented seasonal exacerbations in 419 subjects with moderate-to-severe persistent allergic asthma, including inner city children, adolescents and young adults. ${ }^{60}$ The data from placebo-controlled trials have been further validated by real-life studies performed worldwide and recently systematically reviewed by Abraham et al. ${ }^{61}$

Data from completed clinical studies of 1-4 years duration and involving $>7,500$ patients with asthma, rhinitis or related conditions, as well as post-marketing safety data, have confirmed a high level of safety and tolerability with omalizumab treatment, ${ }^{62,63}$ with a placebo-like tolerability profile and no increased risk of omalizumab-related hypersensitivity reactions, immune system abnormalities, cardiovascular events, cancer, parasitic infections or other relevant diseases. Furthermore, no measurable anti-omalizumab antibodies were produced in patients treated up to 4 years. 
In essence, the role of omalizumab as the only current agent with a specific target that functions as a stratified or multitargeted therapy and has been demonstrated to be safe and effective in the context of currently recommended treatments makes it unique in the treatment of allergic asthma, the most easily recognized of the "asthma phenotypes".

Appropriate patient selection is a key aspect for successful anti-IgE therapy of severe asthma, with the best therapeutic results likely to be achieved by treating severe, inadequately controlled and oral steroid-dependent asthmatics experiencing frequent disease exacerbations. Identifying reliable biomarkers that can predict response to therapy and help define candidate patients more suited for a given treatment is an important and ongoing focus in developing biological therapies, such as omalizumab, which can modify specific pathogenic mechanisms based on precise genotype characterization in the individual patient. In this regard, the EXTRA study has demonstrated that high baseline values of peripheral blood eosinophils can be regarded as a reliable biomarker of Th2 cell-driven allergic inflammation in patients with allergic asthma, especially in association with high levels of fractional exhaled nitric oxide (FeNO) and serum periostin. ${ }^{64}$ These three biomarkers make it possible to predict a positive therapeutic response to omalizumab in terms of decreasing asthma exacerbations. Furthermore, omalizumab has been shown to be associated with significant decreases in sputum and peripheral blood eosinophils in patients with asthma, ${ }^{65,66}$ supporting the role of omalizumab in reducing inflammatory activity in the airways of patients with allergic asthma.

The duration of anti-IgE treatment is also an important aspect to consider. The mechanism of action of omalizumab, based on competitive binding to the $\mathrm{C} \varepsilon 3$ domain of the constant fragment of IgE, would suggest that this drug should be used according to a life long schedule in order to block $\operatorname{IgE}$ functions and to avoid potential symptoms relapses and exacerbations. ${ }^{67-69}$ However, there are some indications that improvements in asthma symptoms and lung function may persist for at least 3 years after discontinuation of anti-IgE therapy, ${ }^{70,71}$ suggesting that anti-IgE therapy could modify the natural history of moderate-to-severe uncontrolled asthma in some patients, perhaps due in part to a modulatory action of omalizumab on bronchial remodeling.

\section{Discussion and conclusion}

IgE-mediated allergic asthma still represents a majority of patients with asthma. The recent GINA report redrew the definition of asthma, emphasizing its heterogeneity and the relevance of disease phenotypes, while recognizing specific biological pathways as clinical features to be considered in the management of severe or difficult-to-treat asthma. Indeed, in GINA step 5, anti-IgE treatment with omalizumab is the recommended option when moderate or severe allergic asthma is uncontrolled on step 4 treatment. $^{7}$ To better understand the mechanisms regulating the IgE-mediated mechanisms in allergic asthma, we have herein reviewed the features and functions of IgE receptors and the interactions with different cellular components, such as mast cells and basophils or eosinophils, epithelial cells or smooth muscle cells. These last cells proliferate as a consequence of IgE-driven inflammation, thus leading to exacerbations of respiratory symptoms, airway remodeling and subsequently affecting pulmonary function.

As a better understanding of the molecular mechanisms and pathogenesis of the disease processes underlying allergic asthma, additional agents that inhibit specific pathways will likely be developed, leading to further reductions in the burden of asthma.

\section{Acknowledgments}

All authors attended an editorial meeting hosted by Health Publishing \& Services srl to discuss topics for inclusion. The entire project was made possible thanks to unconditional support from Novartis Farma. Editorial assistance for the manuscript was provided by Ray Hill, an independent medical writer, on behalf of Health Publishing \& Services srl. We also thank Dr Laura Rigoni from Novartis for her valuable scientific contribution and support to this publication.

\section{Author contributions}

The authors are responsible for the content and writing of the paper. All authors planned, researched and drafted the individual section(s) they were responsible for. All authors read and approved the final manuscript and contributed to critically revising the article, and agree to be accountable for all aspects of the work.

\section{Disclosure}

The authors report no conflicts of interest in this work.

\section{References}

1. National Institutes of Health. Global Initiative for Asthma. Global strategy for asthma management and prevention. NHLBI/WHO Workshop Report: NIH Publication No. 95-3659. 1995.

2. McGrath $\mathrm{KW}$, Icitovic N, Boushey HA, et al. A large subgroup of mildto-moderate asthma is persistently noneosinophilic. Am J Respir Crit Care Med. 2012;185(6):612-619.

3. Wenzel SE, Schwartz LB, Langmack EL, et al. Evidence that severe asthma can be divided pathologically into two inflammatory subtypes with distinct physiologic and clinical characteristics. Am J Respir Crit Care Med. 1999;160(3):1001-1008. 
4. Simpson JL, Scott R, Boyle MJ, Gibson PG. Inflammatory subtypes in asthma: assessment and identification using induced sputum. Respirology. 2006;11(1):54-61.

5. Bacci E, Latorre M, Cianchetti S, et al. Transient sputum eosinophilia may occur over time in non-eosinophilic asthma and this is not prevented by salmeterol. Respirology. 2012;17(8):1199-1206.

6. Wenzel SE. Asthma: defining of the persistent adult phenotypes. Lancet. 2006;368(9537):804-813.

7. Global Initiative for Asthma (GINA) [homepage on the Internet]. Global strategy for asthma management and prevention. Updated 2017. Available from: http://www.ginasthma.org/. Accessed May 25, 2017

8. Reddel HK, Taylor DR, Bateman ED, et al. An official American Thoracic Society/European Respiratory Society statement: asthma control and exacerbations: standardizing endpoints for clinical asthma trials and clinical practice. Am J Respir Crit Care Med. 2009;180(1):59-99.

9. National Asthma Education and Prevention Program. Expert panel report 3 (EPR-3): guidelines for the diagnosis and management of asthmasummary report 2007. J Allergy Clin Immunol. 2007;120(5 supp1): S94-S138.

10. National Institute for Health and Care Excellence (NICE) [webpage on the Internet]. NICE Asthma Guidelines; 2013. Available from: http://www.nice.org.uk/guidance/conditions-and-diseases/respiratoryconditions/asthma. Accessed September 12, 2016.

11. Antonicelli L, Bucca C, Neri M, et al. Asthma severity and medical resource utilisation. Eur Respir J. 2004;23(5):723-729.

12. Accordini S, Corsico AG, Braggion M, et al. The cost of persistent asthma in Europe: an international population-based study in adults. Int Arch Allergy Immunol. 2013;160(1):93-101.

13. Mosbech H, Deckelmann R, de Blay F, et al. Standardized quality (SQ) house dust mite sublingual immunotherapy tablet (ALK) reduces inhaled corticosteroid use while maintaining asthma control: a randomized, double-blind, placebo-controlled trial. J Allergy Clin Immunol. 2014;134(3):568.e7-575.e7.

14. Paggiaro P, Bacci E. Montelukast in asthma: a review of its efficacy and place in therapy. Ther Adv Chronic Dis. 2011;2(1):47-58.

15. Kerstjens HA, Engel M, Dahl R, et al. Tiotropium in asthma poorly controlled with standard combination therapy. N Engl J Med. 2012; 367(13):1198-1207.

16. Rossi R, De Palma A, Benazzi L, Riccio AM, Canonica GW, Mauri P. Biomarker discovery in asthma and COPD by proteomic approaches. Proteomics Clin Appl. 2014;8(11-12):901-915.

17. Braido F, Holgate S, Canonica GW. From "blockbusters" to "biosimilars": an opportunity for patients, medical specialists and health care providers. Pulm Pharmacol Ther. 2012;25(6):483-486.

18. Drazen JM. A step toward personalized asthma treatment. $N$ Engl $J$ Med. 2011;365(13):1245-1246.

19. Gould HJ, Sutton BJ. IgE in allergy and asthma today. Nat Rev Immunol. 2008;8(3):205-217.

20. Kraft S, Kinet JP. New developments in FceRI regulation, function and inhibition. Nat Rev Immunol. 2007;7(5):365-378.

21. Wan T, Beavil RL, Fabiane SM, et al. The crystal structure of IgE Fc reveals an asymmetrically bent conformation. Nat Immunol. 2002; 3(7):681-686.

22. Maurer D, Fiebiger S, Ebner C, et al. Peripheral blood dendritic cells express Fc epsilon RI as a complex composed of Fc epsilon RI alpha- and Fc epsilon RI gamma-chains and can use this receptor for IgE-mediated allergen presentation. J Immunol. 1996;157(2): 607-616.

23. Redhu NS, Gounni AS. The high affinity IgE receptor (FceRI) expression and function in airway smooth muscle. Pulm Pharmacol Ther. 2013;26(1):86-94.

24. Campbell AM, Vignola AM, Chanez P, Godard P, Bousquet J. Lowaffinity receptor for IgE on human bronchial epithelial cells in asthma. Immunology. 1994;82(4):506-508.

25. Foster B, Metcalfe DD, Prussin C. Human dendritic cell 1 and dendritic cell 2 subsets express FcepsilonRI: correlation with serum IgE and allergic asthma. J Allergy Clin Immunol. 2003;112(6):1132-1138.
26. Sihra BS, Kon OM, Grant JA, Kay AB. Expression of high-affinity IgE receptors (Fc epsilon RI) on peripheral blood basophils, monocytes, and eosinophils in atopic and nonatopic subjects: relationship to total serum IgE concentrations. J Allergy Clin Immunol. 1997;99(5):699-706.

27. Malveaux FJ, Conroy MC, Adkinson NF Jr, Lichtenstein LM. IgE receptors on human basophils. Relationship to serum IgE concentration. J Clin Invest. 1978;62(1):176-181.

28. MacGlashan D Jr. IgE receptor and signal transduction in mast cells and basophils. Curr Opin Immunol. 2008;20(6):717-723.

29. Weskamp G, Ford JW, Sturgill J, et al. ADAM10 is a principal 'sheddase' of the low-affinity immunoglobulin E receptor CD23. Nat Immunol. 2006; 7(12):1293-1298.

30. Platzer B, Ruiter F, van der Mee J, Fiebiger E. Soluble IgE receptorselements of the IgE network. Immunol Lett. 2011;141(1):36-44.

31. Lambrecht BN, Hammad H. The immunology of asthma. Nat Immunol. 2015;16(1):45-56.

32. Kambayashi T, Koretzky GA. Proximal signaling events in Fc epsilon RI-mediated mast cell activation. J Allergy Clin Immunol. 2007; 119(3):544-552.

33. Molfetta R, Quatrini L, Gasparrini F, Zitti B, Santoni A, Paolini R. Regulation of fc receptor endocytic trafficking by ubiquitination. Front Immunol. 2014;5:449.

34. Stingl G, Maurer D. IgE-mediated allergen presentation via Fc epsilon RI on antigen-presenting cells. Int Arch Allergy Immunol. 1997; 113(1-3):24-29.

35. Khan SH, Grayson MH. Cross-linking IgE augments human conventional dendritic cell production of CC chemokine ligand 28. J Allergy Clin Immunol. 2010;125(1):265-267.

36. Maurer D, Fiebiger E, Reininger B, et al. Fc epsilon receptor I on dendritic cells delivers IgE-bound multivalent antigens into a cathepsin S-dependent pathway of MHC class II presentation. J Immunol. 1998;161(6):2731-2739.

37. Novak N, Bieber T, Katoh N. Engagement of Fc epsilon RI on human monocytes induces the production of IL-10 and prevents their differentiation in dendritic cells. J Immunol. 2001;167(2):797-804.

38. Lynch JP, Mazzone SB, Rogers MJ, et al. The plasmacytoid dendritic cell: at the cross-roads in asthma. Eur Respir J. 2014;43(1):264-275.

39. Gounni AS, Lamkhioued B, Ochiai K, et al. High-affinity IgE receptor on eosinophils is involved in defence against parasites. Nature. 1994;367(6459):183-186.

40. Rajakulasingam K, Durham SR, O’Brien F, et al. Enhanced expression of high-affinity IgE receptor (Fc epsilon RI) alpha chain in human allergen-induced rhinitis with co-localization to mast cells, macrophages, eosinophils, and dendritic cells. J Allergy Clin Immunol. 1997; 100(1):78-86

41. Smith SJ, Ying S, Meng Q, et al. Blood eosinophils from atopic donors express messenger RNA for the alpha, beta, and gamma subunits of the high-affinity $\mathrm{IgE}$ receptor (Fc epsilon $\mathrm{RI}$ ) and intracellular, but not cell surface, alpha subunit protein. J Allergy Clin Immunol. 2000; 105(2 pt 1):309-317.

42. Kita H, Kaneko M, Bartemes KR, et al. Does IgE bind to and activate eosinophils from patients with allergy? J Immunol. 1999;162(11):6901-6911.

43. Wang J, Cheng X, Xiang MX, et al. IgE stimulates human and mouse arterial cell apoptosis and cytokine expression and promotes atherogenesis in Apoe-/- mice. J Clin Invest. 2011;121(9):3564-3577.

44. Novak N, Peng WM, Bieber T, Akdis C. FcepsilonRI stimulation promotes the differentiation of histamine receptor 1-expressing inflammatory macrophages. Allergy. 2013;68(4):454-461.

45. Kaminska M, Foley S, Maghni K, et al. Airway remodeling in subjects with severe asthma with or without chronic persistent airflow obstruction. J Allergy Clin Immunol. 2009;124(1):45.e1-4-51.e1-e4.

46. Roth M, Zhong J, Zumkeller C, S'Ng CT, Goulet S, Tamm M. The role of IgE-receptors in IgE-dependent airway smooth muscle cell remodelling. PLoS One. 2013;8(2):e56015.

47. Palaniyandi S, Liu X, Periasamy S, et al. Inhibition of CD23-mediated IgE transcytosis suppresses the initiation and development of allergic airway inflammation. Mucosal Immunol. 2015;8(6):1262-1274. 
48. Palaniyandi S, Tomei E, Li Z, Conrad DH, Zhu X. CD23-dependent transcytosis of $\mathrm{IgE}$ and immune complex across the polarized human respiratory epithelial cells. J Immunol. 2011;186(6):3484-3496.

49. Holgate S, Casale T, Wenzel S, Bousquet J, Deniz Y, Reisner C. The anti-inflammatory effects of omalizumab confirm the central role of IgE in allergic inflammation. J Allergy Clin Immunol. 2005;115(3): 459-465.

50. Fahy JV, Fleming HE, Wong HH, et al. The effect of an anti-IgE monoclonal antibody on the early- and late-phase responses to allergen inhalation in asthmatic subjects. Am J Respir Crit Care Med. 1997; 155(6):1828-1834.

51. Pelaia G, Vatrella A, Busceti MT, Gallelli L, Terracciano R, Maselli R. Anti-IgE therapy with omalizumab for severe asthma: current concepts and potential developments. Curr Drug Targets. 2015;16(2) 171-178.

52. Pelaia G, Vatrella A, Maselli R. The potential of biologics for the treatment of asthma. Nat Rev Drug Discov. 2012;11(12):958-972.

53. Braunstahl GJ, Chlumsky J, Peachey G, Chen CW. Reduction in oral corticosteroid use in patients receiving omalizumab for allergic asthma in the real-world setting. Allergy Asthma Clin Immunol. 2013;9(1):47.

54. Busse W, Corren J, Lanier BQ, et al. Omalizumab, anti-IgE recombinant humanized monoclonal antibody, for the treatment of severe allergic asthma. J Allergy Clin Immunol. 2001;108(2):184-190.

55. Holgate ST, Chuchalin AG, Hebert J, et al. Efficacy and safety of a recombinant anti-immunoglobulin $\mathrm{E}$ antibody (omalizumab) in severe allergic asthma. Clin Exp Allergy. 2004;34(4):632-638.

56. Solèr M, Matz J, Townley R, et al. The anti-IgE antibody omalizumab reduces exacerbations and steroid requirement in allergic asthmatics. Eur Respir J. 2001;18(2):254-261.

57. Vignola AM, Humbert M, Bousquet J, et al. Efficacy and tolerability of anti-immunoglobulin E therapy with omalizumab in patients with concomitant allergic asthma and persistent allergic rhinitis: SOLAR. Allergy. 2004;59(7):709-717.

58. Humbert M, Beasley R, Ayres J, et al. Benefits of omalizumab as add-on therapy in patients with severe persistent asthma who are inadequately controlled despite best available therapy (GINA 2002 step 4 treatment): INNOVATE. Allergy. 2005;60(3):309-316.

59. Hanania NA, Alpan O, Hamilos DL, et al. Omalizumab in severe allergic asthma inadequately controlled with standard therapy: a randomized trial. Ann Intern Med. 2011;154(9):573-582.

60. Busse WW, Morgan WJ, Gergen PJ, et al. Randomized trial of omalizumab (anti-IgE) for asthma in inner-city children. $N$ Engl J Med. 2011;364(11):1005-1015.

61. Abraham I, Alhossan A, Lee CS, Kutbi H, MacDonald K. 'Real-life' effectiveness studies of omalizumab in adult patients with severe allergic asthma: systematic review. Allergy. 2016;71(5):593-610.

62. Corren J, Casale TB, Lanier B, Buhl R, Holgate S, Jimenez P. Safety and tolerability of omalizumab. Clin Exp Allergy. 2009;39(6):788-797.

63. Rodrigo GJ, Neffen H, Castro-Rodriguez JA. Efficacy and safety of subcutaneous omalizumab vs placebo as add-on therapy to corticosteroids for children and adults with asthma: a systematic review. Chest. 2011;139(1):28-35.
64. Hanania NA, Wenzel S, Rosen K, et al. Exploring the effects of omalizumab in allergic asthma: an analysis of biomarkers in the EXTRA study. Am J Respir Crit Care Med. 2013;187(8):804-811.

65. Djukanovic R, Wilson SJ, Kraft M, et al. Effects of treatment with antiimmunoglobulin E antibody omalizumab on airway inflammation in allergic asthma. Am J Respir Crit Care Med. 2004;170(6):583-593.

66. Kupryś-Lipińska I, Molińska K, Kuna P. The effect of omalizumab on eosinophilic inflammation of the respiratory tract in patients with allergic asthma. Pneumonol Alergol Pol. 2016;84(4):232-243.

67. Pelaia G, Gallelli L, Renda T, et al. Update on optimal use of omalizumab in management of asthma. J Asthma Allergy. 2011;4:49-59.

68. Corren J, Shapiro G, Reimann J, et al. Allergen skin tests and free IgE levels during reduction and cessation of omalizumab therapy. J Allergy Clin Immunol. 2008;121(2):506-511.

69. Ledford D, Busse W, Trzaskoma B, et al. A randomized, multicenter study evaluating Xolair(R) persistency of response after long-term therapy (XPORT). J Allergy Clin Immunol. Epub 2016 Nov 5.

70. Nopp A, Johansson SG, Adedoyin J, Ankerst J, Palmqvist M, Oman H After 6 years with Xolair; a 3-year withdrawal follow-up. Allergy. 2010;65(1):56-60.

71. Baena-Cagnani CE, Teijeiro A, Canonica GW. Four-year follow-up in children with moderate/severe uncontrolled asthma after withdrawal of a 1-year omalizumab treatment. Curr Opin Allergy Clin Immunol. 2015;15(3):267-271.

72. Humbert M, Busse W, Hanania NA, et al. Omalizumab in asthma: an update on recent developments. J Allergy Clin Immunol Pract. 2014; 2(5):525.e1-536.e1.

73. Lantz CS, Yamaguchi M, Oettgen HC, et al. IgE regulates mouse basophil Fc epsilon RI expression in vivo. J Immunol. 1997;158(6): 2517-2521.

74. Yamaguchi M, Lantz CS, Oettgen HC, et al. IgE enhances mouse mast cell Fc(epsilon)RI expression in vitro and in vivo: evidence for a novel amplification mechanism in IgE-dependent reactions. J Exp Med. 1997; 185(4):663-672.

75. Asai K, Kitaura J, Kawakami Y, et al. Regulation of mast cell survival by IgE. Immunity. 2001;14(6):791-800.

76. Kalesnikoff J, Huber M, Lam V, et al. Monomeric IgE stimulates signaling pathways in mast cells that lead to cytokine production and cell survival. Immunity. 2001;14(6):801-811.

77. Cruse G, Kaur D, Yang W, Duffy SM, Brightling CE, Bradding P. Activation of human lung mast cells by monomeric immunoglobulin E. Eur Respir J. 2005;25(5):858-863.

78. Kashiwakura J, Okayama Y, Furue M, et al. Most highly cytokinergic IgEs have polyreactivity to autoantigens. Allergy Asthma Immunol Res. 2012;4(6):332-340

79. Kitaura J, Song J, Tsai M, et al. Evidence that IgE molecules mediate a spectrum of effects on mast cell survival and activation via aggregation of the FceRI. Proc Natl Acad Sci U S A. 2003;100(22):12911-12916.

80. Owen CE. Immunoglobulin E: role in asthma and allergic disease: lessons from the clinic. Pharmacol Ther. 2007;113(1):121-133.

\section{Publish your work in this journal}

Drug Design, Development and Therapy is an international, peerreviewed open-access journal that spans the spectrum of drug design and development through to clinical applications. Clinical outcomes, patient safety, and programs for the development and effective, safe, and sustained use of medicines are the features of the journal, which

\section{Dovepress}

has also been accepted for indexing on PubMed Central. The manuscript management system is completely online and includes a very quick and fair peer-review system, which is all easy to use. Visit http://www.dovepress.com/testimonials.php to read real quotes from published authors. 